\title{
Determination of the Physical Properties of Near Surface Layers of Omerulu Area, Nigeria, Using Seismic Refraction Method
}

\author{
Olowofela Joseph Adeniyi ${ }^{1}$, Akinyemi Olukayode Dewunmi ${ }^{1}$, Odumosu Olutayo ${ }^{2}$, \\ Ajani Olumide Oyewale , * $^{3}$ \\ ${ }^{1}$ Department of Physics, Federal University of Agriculture (FUNAAB), Abeokuta, Nigeria \\ ${ }^{2}$ Exploration Unit, United Geophysical Company, Warri, Nigeria \\ ${ }^{3}$ Department of Physics and Solar Energy, Bowen University, Iwo, Nigeria
}

Email address:

aj_ani2000@yahoo.com (O. O. Ajani)

*Corresponding author

\section{To cite this article:}

Olowofela Joseph Adeniyi, Akinyemi Olukayode Dewunmi, Odumosu Olutayo, Ajani Olumide Oyewale. Determination of the Physical Properties of Near Surface Layers of Omerulu Area, Nigeria, Using Seismic Refraction Method. International Journal of Oil, Gas and Coal Engineering. Vol. 5, No. 5, 2017, pp. 97-115. doi: 10.11648/j.ogce.20170505.15

Received: April 5, 2017; Accepted: April 20, 2017; Published: October 24, 2017

\begin{abstract}
Seismic refraction method is a geophysical technique used to study physical properties of the subsurface such as layer thicknesses, travel times and velocities of seismic signals through the layers. The process of turning seismic refraction data to useful information involves use of first arrival times and offsets. In this study, the near surface investigation of the physical properties of the unconsolidated and consolidated layers was carried out in Omerelu, Rivers State of Nigeria. Omerelu lies between latitude $05^{\circ} 08^{\prime} \mathrm{N}$ and $05^{\circ} 13^{\prime} \mathrm{N}$ and longitude $06^{\circ} 51^{\prime} \mathrm{E}$ and $06^{\circ} 58^{\prime} \mathrm{E}$. Previous investigations were based on refection method in which the near surface effect caused misalignment in the deeper horizons observed in the final stack of the reflection data. This problem was solved by running a seismic refraction survey over the area. The study involved identification of points at which data would be acquired to give a good overview of the area under consideration. Twelve sampling points were picked with a grid of approximately $4 \times 4 \mathrm{~km}$. A $100 \mathrm{~m}$ line with two source points at each end was cleared at each data acquisition point after which the coordinates were taken using Leica Total station (TC 1203 survey equipment). Seismic signals were recorded using OYO McSeis 160M coupled with a 12-geophone harness along with a blasting unit. Upsphere processing software was used to plot time - offset graphs to determine the velocities of the unconsolidated and consolidated layers. The intercept times were also graphically obtained and used to determine the thickness of the unconsolidated layer. Results show that the thickness of unconsolidated/weathered layer in the study area varies between 12.25 and $13.60 \mathrm{~m}$, while the velocities of the unconsolidated and the consolidated layers vary between $500-550 \mathrm{~m} / \mathrm{s}$ and $1790-1875 \mathrm{~m} / \mathrm{s}$ respectively. The results obtained when applied to the reflection data, were able to resolve the static problems; thereby increasing and improving the quality of data available on the lithology of the study area.
\end{abstract}

Keywords: Arrival Times, Offsets, Misalignment, Intercept Time, Seismic Refraction Data, Consolidated Layers, Unconsolidated Layers

\section{Introduction}

Refraction seismology is all about a geophysical method that maps geological structure using travel times of head waves. Head waves are elastic waves that enter a high velocity medium (refractor) near the critical angle and travel in the high velocity medium nearly parallel to the refractor surface before returning to the surface of the Earth [18]. The objective in refraction surveys is to measure the arrival times of head waves as a function of source - receiver distance so that the depth to the refractors in which they travel can be determined.

The main variations among refraction methods lie in the 
user's approach to interpretation; hence, in data processing. The classical refraction method is the intercept-time method. Other interpretation methods include the reciprocal method [9], based on [5], and the delay-time method [14]. Palmer [16] developed the generalized reciprocal method. An excellent reference by [12] and [19] discussed modern refraction techniques.

Seismic refraction is a geophysical principle governed by Snell's law. Named after Dutch mathematician, Willebrord Snellius, one of its discoverers, Snell's law states that the sine's of the angles of incidence and refraction is equivalent to the ratio of velocities in the two media, or equivalent to the opposite ratio of the indices of refraction and incidence:

$$
\begin{array}{r}
\frac{\operatorname{Sin} \theta_{1}}{\operatorname{Sin} \theta_{2}}=\frac{v_{1}}{v_{2}}=\frac{n_{1}}{n_{2}} \\
\text { or } n_{2} \cdot \sin \theta_{1}=n_{1} \cdot \sin \theta_{2}
\end{array}
$$

$\theta_{1}$ and $\theta_{2}$ are angles of incidence and refraction respectively; $v_{1}$ and $v_{2}$ are velocities of travel through layers 1 and 2 respectively; $n_{1}$ and $n_{2}$ are refractive indices of layers 1 and 2 respectively.

Snell's law follows from Fermat's principle of least time, which in turn follows from the propagation of light as waves.

The field methods used in refraction studies include reverse refraction, singled -ended profiles that do not allow the analysis of dip and classic fan-shooting of the type used in the oil industry for salt-dome exploration. For some near surface applications such as finding the edges of buried garbage dumps and locating near-surface voids.

More than ever before, people in academia and industry are using near-surface seismology as a non-invasive tool for determining the physical properties and geometry of the upper 200 meters of the subsurface [8].

Refraction experiments are based on the times of arrival of the initial ground movement generated by a source recorded at a variety of distances. Later arrivals in the recorded ground motion are discarded. Thus, the data set derived from refraction experiments consists of a series of times versus distances. These are then interpreted in terms of the depths to subsurface interfaces and the speeds at which motion travels through the subsurface within each layer. These speeds are determined by a set of physical constants, called elastic parameters that describe the material.

During data acquisition individual data records are displayed as variable area wiggle traces displaying travel time against distance. This provides an important check on the quality of the data. Following acquisition wiggle traces are used to display the data during picking of the first-arrivals for each geophone position and source [4].

Any existing ground information such as borehole and trial pit logs, is overlain on the depth profile in order to help calibrate the seismic results and then provide an indication of the level of correlation along the survey line. The refractor depth is displayed as a series of overlapping arcs that represent the solutions for each geophone in the array. The refractor can lie anywhere on the arcs below the intersections with adjacent arcs.

A shallow refraction crew generates energy from a single source. It uses low frequency geophones $(2-5$ Hertz) and low frequency recording methods to obtain refraction data. The offset distance between source and detector is designed to record shallow refraction data [7].

\section{Theoretical Background}

When a force is applied to a material, it deforms. This means that the particles of the material are displaced from their original positions. Provided the force does not exceed a critical value, the displacements are reversible; the particles of the material return to their original positions when the force is removed, and no permanent deformation results. This is called elastic behavior [13].

The laws of elastic deformation are illustrated by the following example. Consider a right cylindrical block of height $\mathrm{h}$ and cross-sectional area $\mathrm{A}$, subjected to a force $\mathrm{F}$ which acts to extend the block by the amount $\Delta \mathrm{h}$.

Experiments show that for elastic deformation $\Delta \mathrm{h}$ is directly proportional to the applied force and to the unstretched dimension of the block, but is inversely proportional to the cross-section of the block. That is,

$$
\begin{aligned}
\Delta h & \propto \frac{F h}{A} \\
\frac{F}{A} & \propto \frac{\Delta h}{h}
\end{aligned}
$$

When the area $A$ becomes infinitesimally small, the limiting value of the force per unit area $(F / A)$ is called the stress $\sigma$.

$$
\sigma=\frac{F}{A}
$$

When $\mathrm{h}$ is infinitesimally small, the fractional change in dimension $(\Delta h / h)$ is called the strain $\varepsilon$, which is a dimensionless quantity.

$$
\varepsilon=\frac{\Delta h}{h}
$$

Equation (4) states that, for elastic behavior, the strain in a body is proportional to the stress applied to it. This linear relationship is called Hooke's law. It forms the basis of elasticity theory.

Beyond a certain value of the stress, called the proportionality limit, Hooke's law no longer holds.

Figure 1 illustrates progressive positions of the wavefront associated with energy travelling directly through an upper layer and energy critically refracted in a lower layer from a seismic source. Direct and refracted ray paths to a detector at $\mathrm{D}$, a distance $X$ from the source are also shown. The layer 
velocities are $V_{1}, V_{2}$ and the refracting interface is at depth $Z$.

The direct ray travels horizontally through the top of the upper layer from $A$ to $D$ at velocity $V_{1}$. The refracted ray travels down to the interface and back up to the surface at velocity $\mathrm{V}_{1}$ along the slant paths $\mathrm{AB}$ and $\mathrm{CD}$ that are inclined at the critical angle $\theta$ and travels along the interface between $\mathrm{B}$ and $\mathrm{C}$ at the higher velocity $\mathrm{V}_{2}$. The total travel time along the refracted raypath $\mathrm{ABCD}$ is given by:
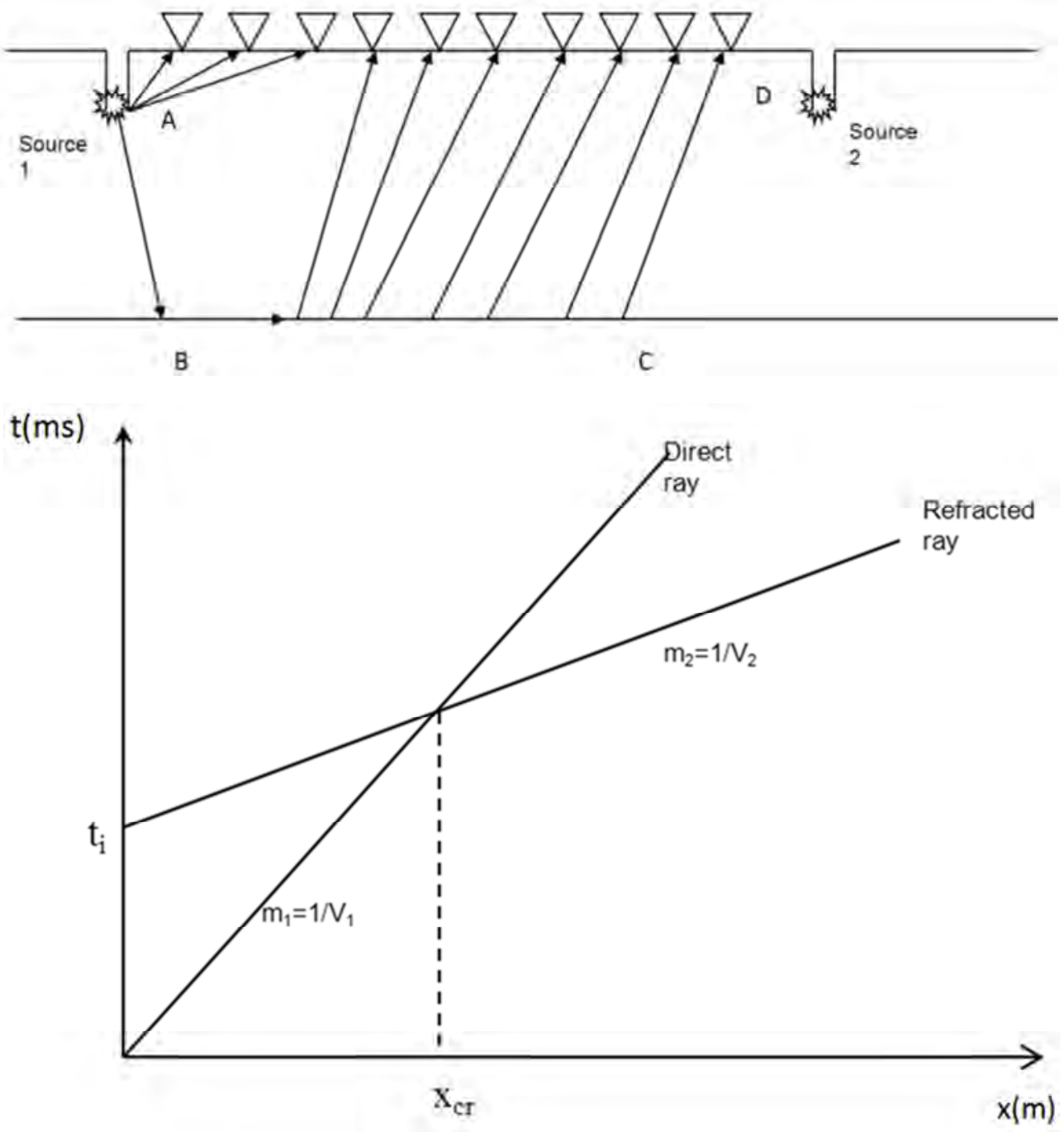

Figure 1. Analysis of refracted ray path.

$$
t=t_{A B}+t_{B C}+t_{C D}=\frac{z}{v_{1} \cos \theta}+\frac{x-2 z \tan \theta}{v_{2}}+\frac{z}{v_{1} \cos \theta}
$$

Since Snell's law states that $\sin \theta=\frac{v_{1}}{v_{2}}$ and $\cos \theta=\sqrt{1-\frac{v_{1}^{2}}{v_{2}^{2}}}$, the travel time equation may be expressed in a number of different forms, the most general form being:

$$
\begin{array}{r}
t=\frac{X \sin \theta}{v_{1}}+\frac{2 z \cos \theta}{v_{1}} \\
\text { or } t=\frac{x}{v_{s}}+\frac{2 z\left(v_{2}^{2}-v_{1}^{2}\right)^{\frac{1}{2}}}{v_{1} v_{2}}
\end{array}
$$

$$
\text { or } t=\frac{x}{v_{2}}+t_{i}
$$

where plotting $t$ against $x, t_{i}$ is the intercept on the time axis of a travel-fime curve or time-distance curve having a gradient of $\frac{1}{v_{2}} \cdot t_{i}$ known as the intercept time, is given by:

$$
t_{i}=\frac{2 z\left(v_{2}^{2}-v_{1}^{2}\right)^{\frac{1}{2}}}{v_{1} \cdot v_{2}}
$$

$v_{l}=$ velocity of $1^{\text {st }}$ layer $=1 /$ slope of $1^{\text {st }}$ line segment from origin

$v_{2}=$ velocity of $2^{\text {nd }}$ layer $=1 /$ slope of $2^{\text {nd }}$ line segment from intercept

Solving for refractor depth: 


$$
\mathrm{z}=\frac{t_{1} \cdot v_{1} \cdot v_{2}}{2 \cdot \sqrt{v_{2}^{2}-v_{1}^{2}}}
$$

Thus by analysis of the travel-time curves of direct and refracted arrivals, $v_{1}$ and $v_{2}$ can be derived (reciprocal of the gradient of the relevant travel-time curve) and from the intercept time $t_{1}$, the refractor depth $z$ can be determined [15].

Seismic body waves which can either be P-waves (propagating through the medium in the same direction as the particles constituting the medium) or S-waves (propagating in a perpendicular direction to the particle constituting the medium). In an homogenous, isotropic media, the velocities of $\mathrm{P}$ and $\mathrm{S}$ - waves are given by

$$
\begin{aligned}
& V_{p}=\sqrt{\frac{\left(\frac{4}{3} \mu+k\right)}{\rho}} \\
& V_{s}=\sqrt{\frac{\mu}{\rho}}
\end{aligned}
$$

where $V_{p}$ and $V_{s}$ are the $P$ and $S$ wave velocities of the medium, $\rho$ is the density of the medium, $\mu$ and $\mathrm{k}$ are referred to as the shear and bulk moduli of the medium ( also known as the elastic parameters of the medium).

Any change in rock or soil property that causes $\rho, \mu$ or $k$ to change will cause seismic wave speed to change, thereby offering the potential enabling the mapping of many subsurface features.

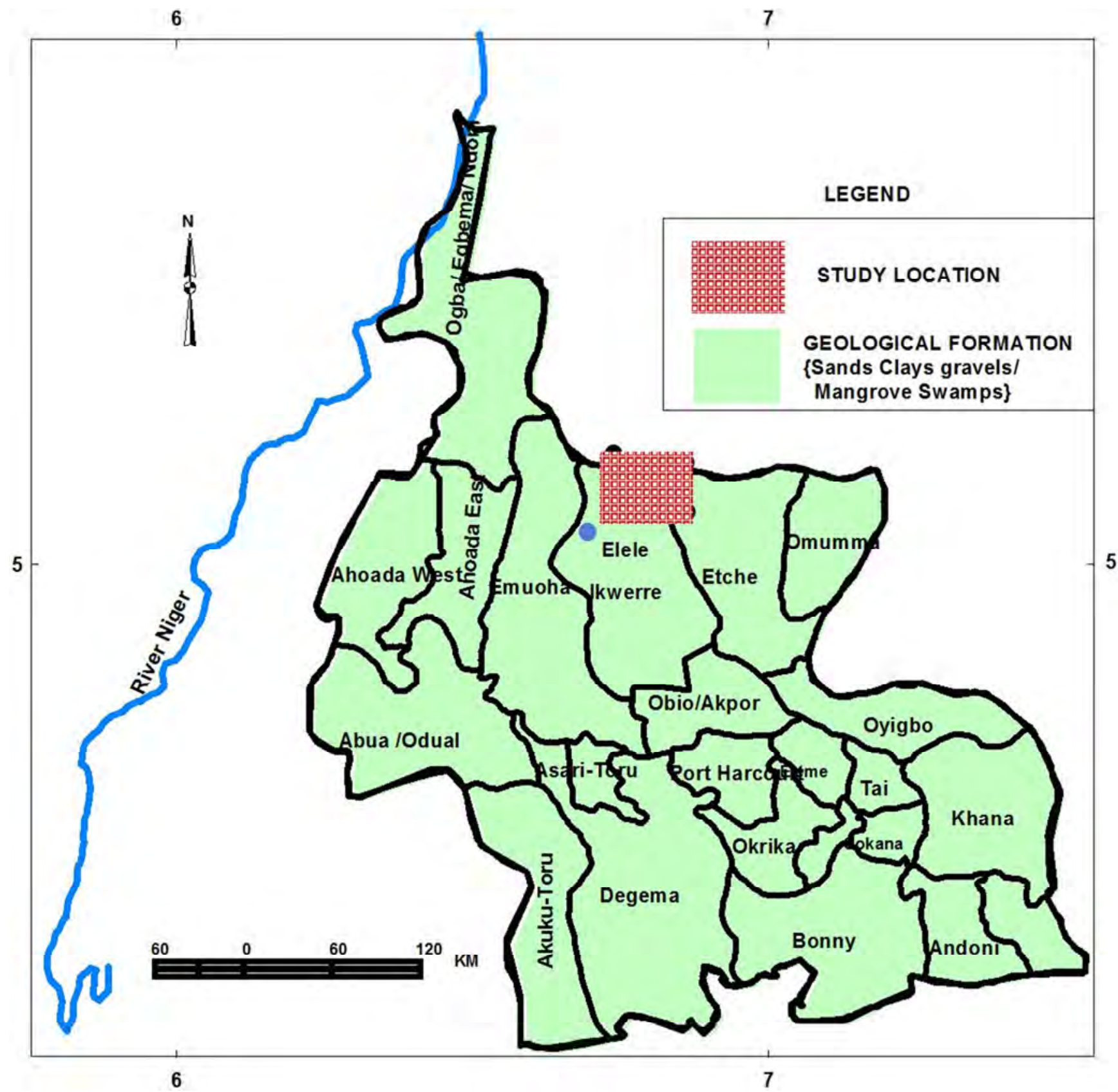

Figure 2. Map showing location of the study area (Adapted from Nigerian Geological Survey Agency 2006). 


\section{Field Work in Omerulu Area}

An earlier work reported in Ajani, et al [1], describes the geographic formation of the study area, the study area lies between latitude $05^{\circ} 08^{\prime} \mathrm{N}$ and $05^{\circ} 13^{\prime} \mathrm{N}$ and longitude $06^{\circ}$ $51^{\prime} \mathrm{E}$ and $06^{\circ} 58^{\prime} \mathrm{E}$. It is situated in the River State part of the Niger Delta, Nigeria. Some of the relatively large urban settlements around study area are Omerulu, Apani, Umuapu, Isu-Etche and Rison palm plantation. The vegetation of the area is mainly farm land, palm plantation, thick bush and rubber plantation. At the time of this study, it was during raining season and humidity was high at this period.

The tertiary lithostratigraphic sequence of the Niger delta consists in ascending order, of the Akata, Agbada and Benin formations, which make up an overall regressive elastic sequence about 30,000 - 39,000ft( $(9,000$ - 12,000m) thick [6].

The study took place using $4 \mathrm{~km} \times 4 \mathrm{~km}$ grid between acquisition points. Leica Total station TC 1203 survey instrument was used for taking survey field data which were converted to coordinates and elevations using GP Seismic software. This is a specialized survey processing data.

The source points were drilled manually using what is commonly called thumping method. This involved an individual using $3 \mathrm{~m}$ steel casing to make $1 \mathrm{~m}$ hole. The drilled hole was loaded with $0.2 \mathrm{~kg}$ dynamite with detonator and firing line attached to connect the dynamite to the instrument for initiation of seismic energy source. The sources were buried so that most of the source energy could penetrate the subsurface.

OYO McSeis $160 \mathrm{M}$ and 12 - receiver geophone string is then deployed to acquire seismic data. The 12- receivers were planted across the cleared line and covered $85 \mathrm{~m}$. Two holes were drilled at both ends of the laid geophone string.

The instrument was used to initiate the dynamite while the signal was received by the receiver and transmitted to the instrument for recording.

After the field data acquisition the data were further analysed and processed. The seismic refraction data were processed using excel-based software called Upsphere.

The first and the main template has fields where general description of the study, identification number of each data set, depth of the source, the coordinates of the study area, etc can be inputted. It also has fields to input offset for each receiver deployed and first arrival times for each offset. It has fields where type of soil encountered during drilling can be entered.

The data obtained were then plotted. Each plot shows points on the time-offset graph and the break-point can defined for each data set after choosing lines of best-fit for various layers. The program has ability to plot and display as much as 4 layers.

At this point the subsurface velocities and depth of unconsolidated are displayed by the program. This process was repeated for each data sets. The results were inputted into Surfer computer program to create the contour map.

\section{Results and Discussion}

Velocities and results of thickness of the unconsolidated layer are obtained from the field work and analysis. These results indicate the type of waves received at each geophone - direct or refracted waves.

At the acquisition point 1 which is at the south west corner of the study area as shown in Figure 11, the recording was first done and the first breaks were obtained before the reverse recording and obtaining the first breaks. The plots of the data obtained from the forward recording are shown Figure 4 in blue while the plots of the reverse recording are displayed in red.

Four data points fell on the straight line arising from the origin while one data point was slightly offset from the straight line. The data were direct waves received at the five geophones nearest to the source. The reciprocal of the slope gave $522 \mathrm{~m} / \mathrm{s}$ as velocity at which seismic waves travelled through the layer. The remaining seven points defined the second layer. Four data points fell on the straight line, two data points had slight offset below the straight line and one data point was slightly offset above the straight line. These data were refracted waves received by the seven geophones farther away from the source. The reciprocal of the slope gave $1804 \mathrm{~m} / \mathrm{s}$ as velocity at which seismic waves refracted by the second medium travelled to the receivers planted at the surface. The thickness of the unconsolidated layer was derived using equation (12) to be $12.2 \mathrm{~m}$.

The results from the reverse recording indicated a twolayer model as shown in Figure 12. The first layer was derived from five data points recorded by geophones which received the direct waves. Four data points fell on the straight line arising from the origin and one data point had very slight offset from the straight line. The reciprocal of the slope of the straight line gave $514 \mathrm{~m} / \mathrm{s}$ as velocity at which direct seismic waves travelled through the first layer. The second straight line for the reverse recording indicated the second layer. It was derived from the plot of the remaining seven points. Four of the data points were on the straight line, two data points were slightly offset above the straight line and one data point was slightly offset below the straight line. The straight line gave a slope whose reciprocal worked out to be $1806 \mathrm{~m} / \mathrm{s}$. This is the velocity at which seismic waves travelled through the second medium. The thickness of the unconsolidated layer was $12.1 \mathrm{~m}$.

The difference in the velocity results for the first medium and the difference in the velocity results for the second medium are insignificant when compared in reference to the list of seismic velocities of materials in Table 1 . The velocity bands have not been exceeded in both cases and therefore the first medium can be considered as homogenous and likewise the second medium.

The average velocity of the first layer from the two recordings is $518 \mathrm{~m} / \mathrm{s}$ and the average velocity for the second layer is $1805 \mathrm{~m} / \mathrm{s}$. The average thickness is $12.15 \mathrm{~m}$. 
Table 1. Seismic velocities of some earth materials.

\begin{tabular}{lll}
\hline Materials & P wave Velocity $(\mathbf{m} / \mathbf{s})$ & S wave Velocity $(\mathbf{m} / \mathbf{s})$ \\
\hline Air & $300-332$ & NA \\
Petroleum & $1300-1400$ & NA \\
Water & $1400-1500$ & NA \\
Clay & $1000-2500$ & $400-1000$ \\
Sand (Unsaturated) & $200-1000$ & $80-400$ \\
Sand (Saturated) & $800-2200$ & $320-880$ \\
Sandstone & $1400-4300$ & $700-2800$ \\
Glacial Till (saturated) & $1500-2500$ & $600-1000$ \\
Concrete & 3600 & 2000 \\
Granite & $5500-5900$ & $2800-3000$ \\
Limestone & $5900-6100$ & $2800-3000$ \\
Basalt & 6400 & 3200 \\
\hline
\end{tabular}

(Source: Okwueze, 1996)

Similarly, for the remaining 11-acquisition points, same discussion is applicable with their different layer thickness estimated from the different seismic velocities recorded and calculated.

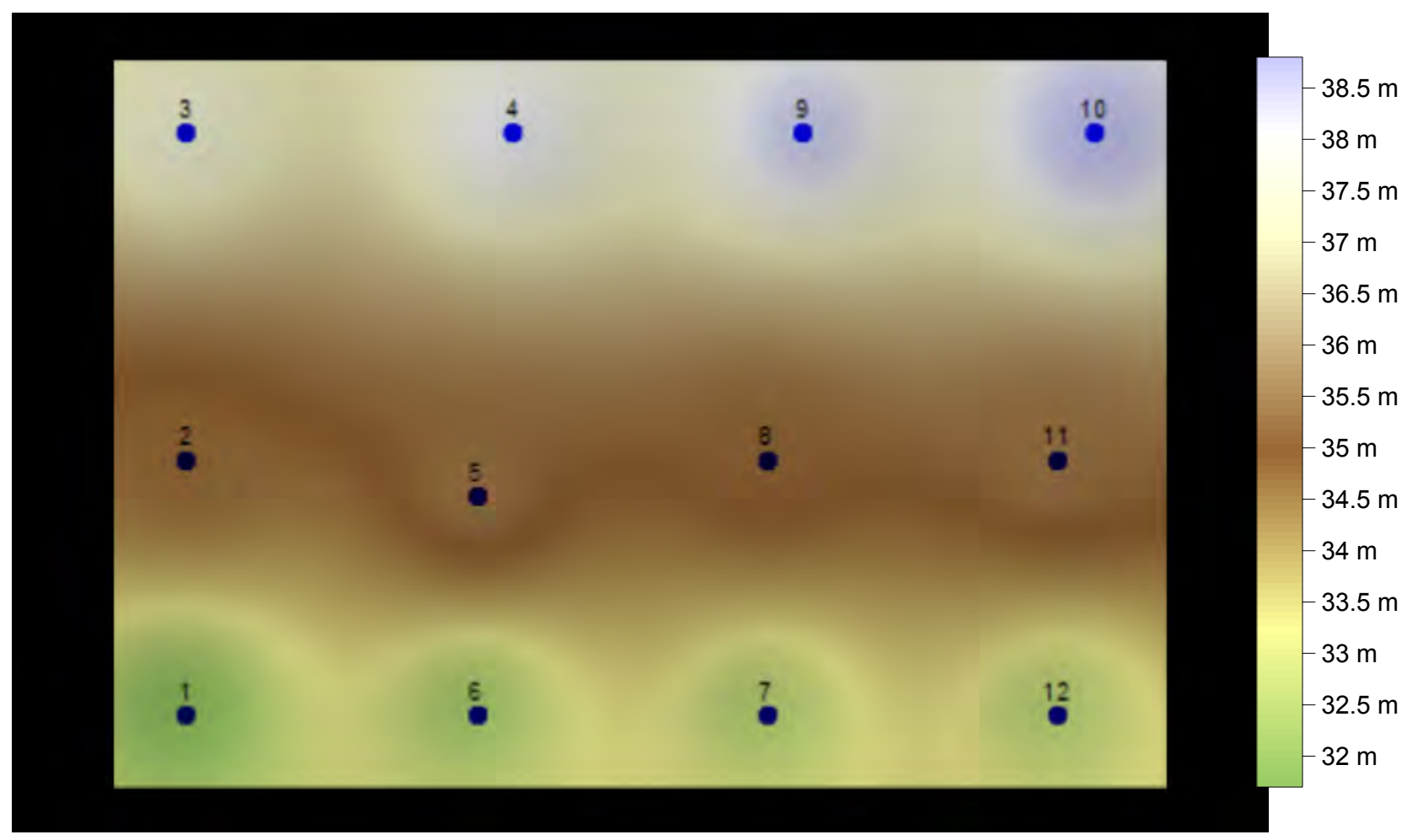

Figure 3. Elevation contour map showing the twelve acquisition points. 


\section{V L DATA PROCESSING}

Project Nam LVL STUDY Contractor:

Party/Proj M

Date Logger 6/20/2008

InstrU Type: McSEIS-160M

Processed ETAYO

Record No: 1

\section{FIELD DATA}

$\operatorname{Depth}(\mathrm{m})$ FB(mSec) FB_2(Reverse)

$\begin{array}{rrr}5 & 9.5 & 9.5 \\ 10 & 19 & 19 \\ 15 & 28 & 26.5 \\ 20 & 39 & 39 \\ 30 & 57 & 57.5 \\ 40 & 67.5 & 68 \\ 50 & 72 & 72 \\ 60 & 78.5 & 78 \\ 70 & 83.5 & 83 \\ 75 & 86 & 86.5 \\ 80 & 89 & 90 \\ 85 & 92.5 & 92\end{array}$

$\begin{array}{llll}\text { UPhole No: } 1 & \text { Drilled Depth }(\mathrm{m}): & 1 \\ \text { Station No: } & 5453-2339 & \text { Logged Depth }(\mathrm{m}): & 0.8 \\ \text { Easting: } & 489359.5 & \text { Shot Depth }(\mathrm{m}): & 0.8 \\ \text { Northing: } & 127202.1 & \text { Offset Dist }(\mathrm{m}): & 0 \\ \text { Elevation: } & 31.7 & \text { Source Type: } & \text { DYNAMITE } \\ \text { Drilled by: } & & \text { Delay TimeBreak: } & \\ \text { Datum(m): } 0 & \text { Static(millisecond): } & 34\end{array}$

DISTANCE TIME GRAPH

Shot - Rec Offest(meters)

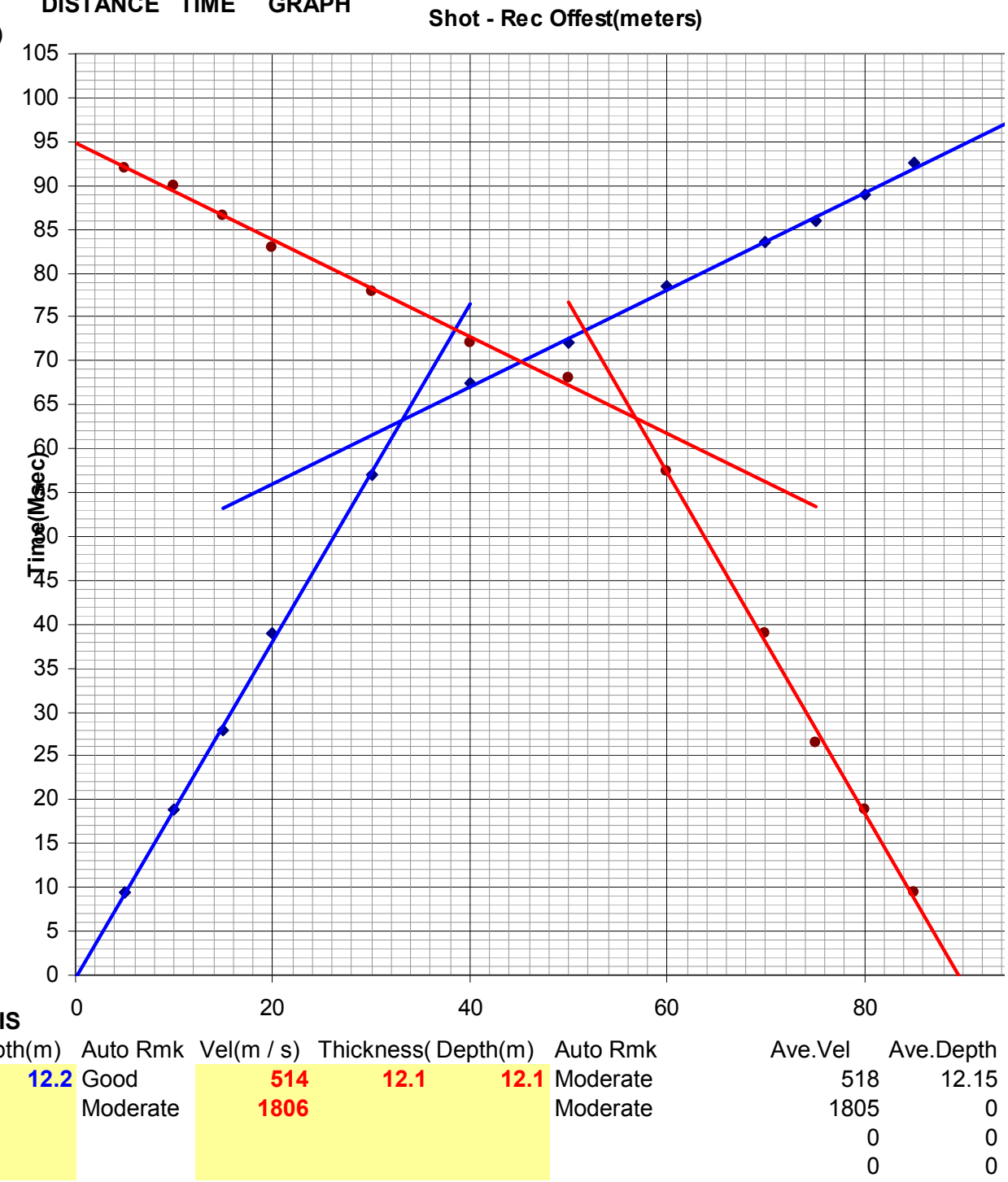

$\begin{array}{lrrrrrr}\text { LAYER 1 } & 522 & 12.2 & 12.2 \text { Good } & 514 & 12.1 & 12.1 \text { Moderate } \\ \text { LAYER 2 } & 1804 & & \text { Moderate } & 1806 & \text { Moderate } & 12.15 \\ \text { LAYER 3 } & & & & & 0 \\ \text { LAYER 4 } & & & & & 0 & 0 \\ 0\end{array}$

REMARK:

Figure 4. First arrival times vs receiver offsets (Acquisition Point 1). 


\section{V L DATA PROCESSING}

Project Nam LVL STUDY

\section{Contractor:}

Party/Proj M

Date Logger 6/20/2008

InstrU Type: McSEIS-160M

Processed ETAYO

Record No: 2

\section{FIELD DATA}

$\operatorname{Depth}(\mathrm{m}) \quad \mathrm{FB}(\mathrm{mSec})$ FB_2(Reverse)

$\begin{array}{rrr}5 & 9.5 & 9.5 \\ 10 & 19.5 & 20 \\ 15 & 27.5 & 28.5 \\ 20 & 39 & 39 \\ 30 & 58.5 & 59 \\ 40 & 69 & 70 \\ 50 & 77 & 78 \\ 60 & 80 & 80 \\ 70 & 86 & 86.5 \\ 75 & 89 & 90 \\ 80 & 92.5 & 92 \\ 85 & 94 & 94\end{array}$

\footnotetext{
VELOCITY ANALYSIS
}

$\begin{array}{ll}\text { UPhole No: } & 2 \\ \text { Station No: } & 5523-2339 \\ \text { Easting: } & 489359.5 \\ \text { Northing: } & 130702.3 \\ \text { Elevation: } & 34.8 \\ \text { Drilled by: } & \\ \text { Datum(m): } & 0\end{array}$

DISTANCE TIME GRAPH

$\begin{array}{ll}\text { Drilled Depth }(\mathrm{m}): & 1 \\ \text { Logged Depth }(\mathrm{m}): & 0.8 \\ \text { Shot Depth }(\mathrm{m}): & 0.8 \\ \text { Offset Dist }(\mathrm{m}): & 0 \\ \text { Source Type: } & \text { DYNAMITE } \\ \text { Delay TimeBreak: } & \\ \text { Static(millisecond): } & 37\end{array}$

Shot - Rec Offest(meters)

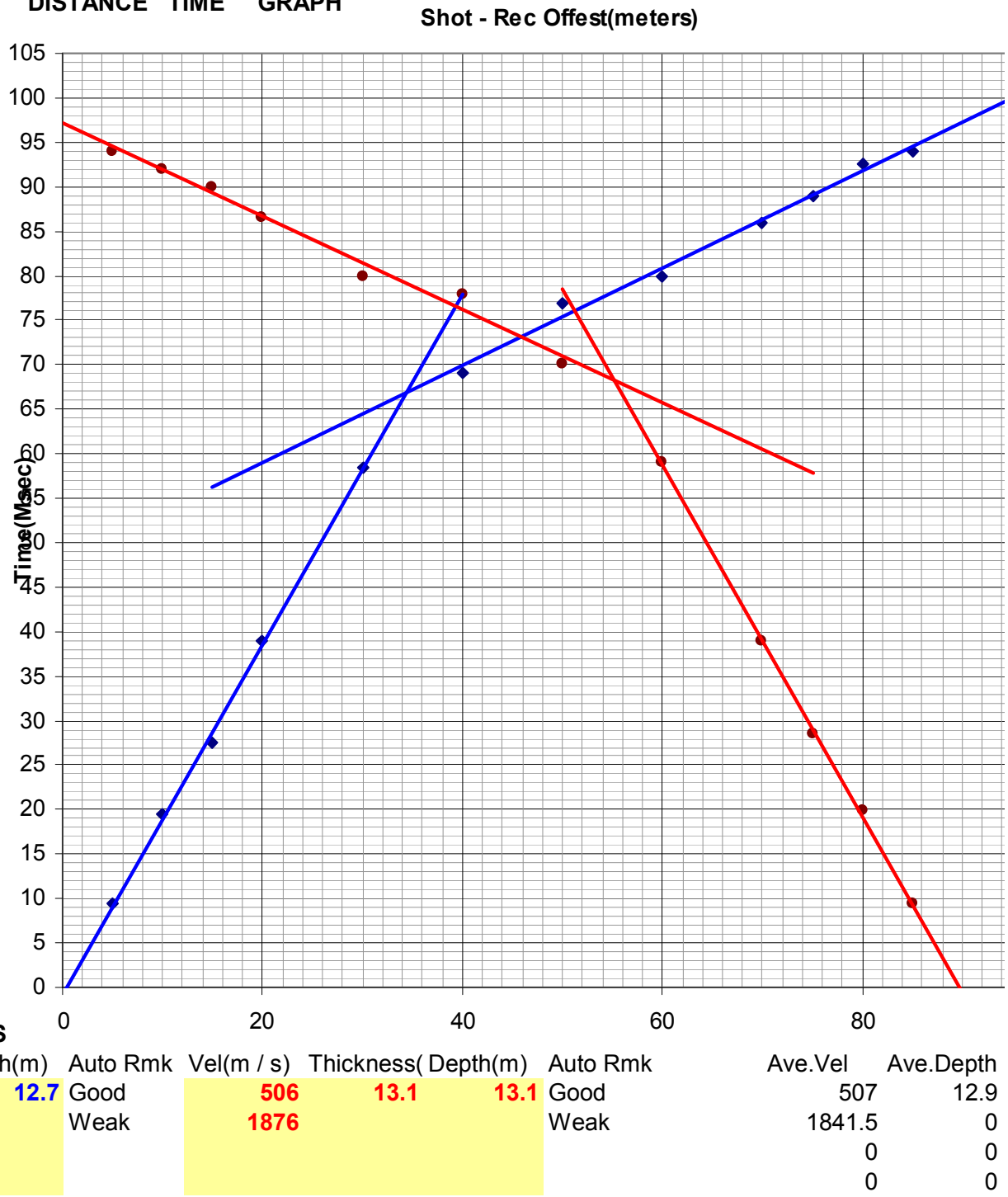

$\begin{array}{lrrrrrrr}\text { LAYER 1 } & 508 & 12.7 & 12.7 \text { Good } & 506 & 13.1 & 13.1 \text { Good } & 12.9 \\ \text { LAYER 2 } & 1807 & & \text { Weak } & 1876 & \text { Weak } & 0 \\ \text { LAYER 3 } & & & & & 0 & 0 \\ \text { LAYER 4 } & & & & & 0 & 0\end{array}$

REMARK:

Figure 5. First arrival times vs receiver offsets (Acquisition Point 2). 


\section{V L DATA PROCESSING}

Project Nam LVL STUDY

Contractor:

Party/Proj M

Date Logger 6/15/2008

InstrU Type: McSEIS-160M

Processed ETAYO

Record No: 3

\section{FIELD DATA}

$\operatorname{Depth}(\mathrm{m})$ FB(mSec) FB_2(Reverse)

$\begin{array}{rrr}5 & 10.5 & 10 \\ 10 & 20 & 20 \\ 15 & 27.5 & 28.5 \\ 20 & 38 & 38 \\ 30 & 60 & 59 \\ 40 & 71 & 71.5 \\ 50 & 77 & 78 \\ 60 & 82 & 82 \\ 70 & 87.5 & 88 \\ 75 & 90 & 90 \\ 80 & 92.5 & 92 \\ 85 & 96 & 96.5\end{array}$

VELOCITY ANALYSIS

UPhole No: 3

Station No: $5613-2339$

Easting: $\quad 489360.2$

Northing: $\quad 135202.4$

Elevation: 37.5

Drilled by:

$\operatorname{Datum}(\mathrm{m})$ : 0
Drilled Depth $(\mathrm{m})$ : 1

Logged Depth $(\mathrm{m}): \quad 0.8$

Shot Depth $(\mathrm{m})$ : $\quad 0.8$

Offset $\operatorname{Dist}(\mathrm{m})$ : $\quad 0$

Source Type: DYNAMITE

Delay TimeBreak:

Static(millisecond): $\quad 39$

\section{DISTANCE TIME GRAPH Shot - Rec Offest(meters)}

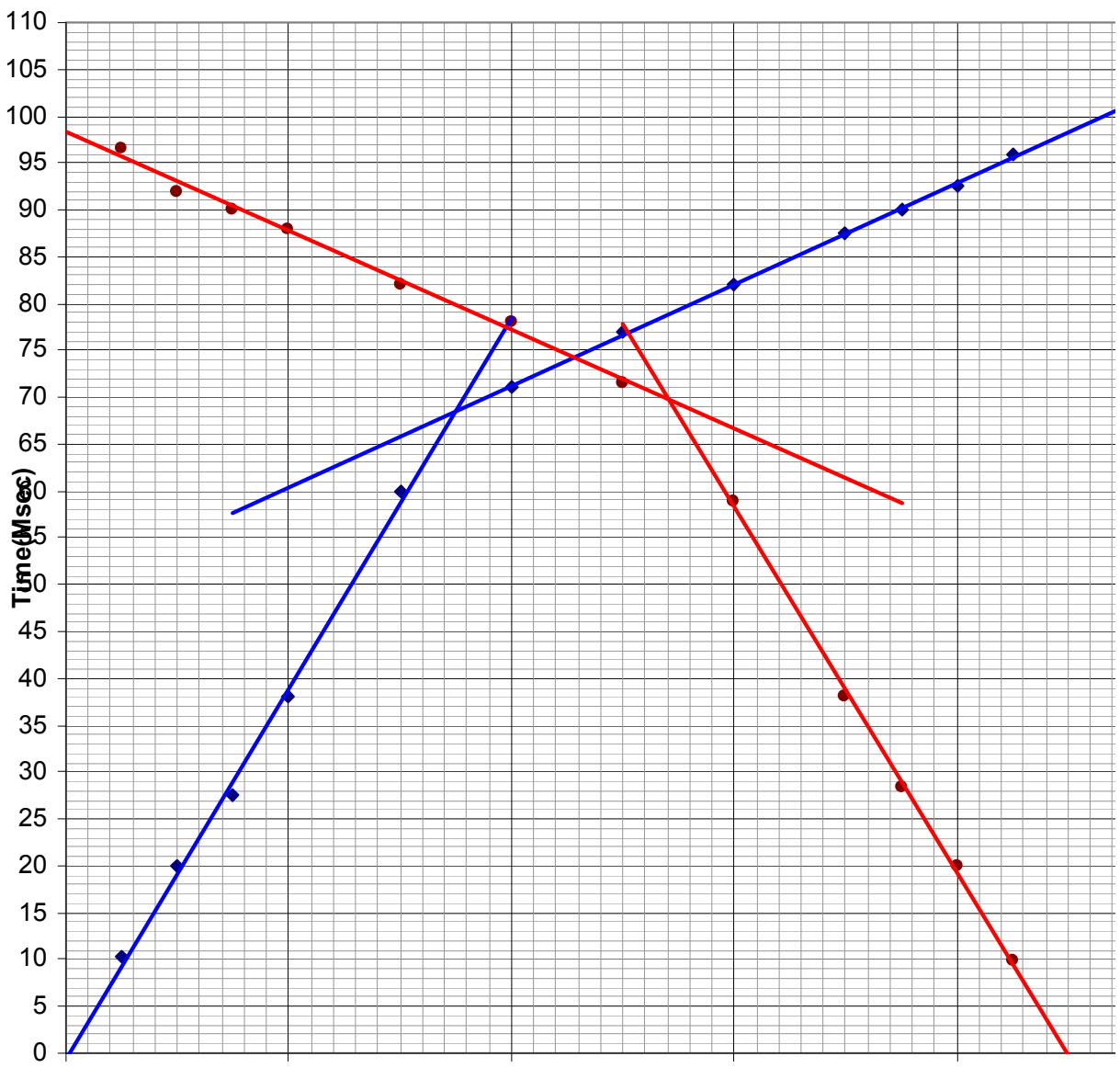

20

40

60

80

$\operatorname{Vel}(\mathrm{m} / \mathrm{s})$ Thickness(Depth $(\mathrm{m})$ Auto Rmk Vel(m/s) Thickness(Depth $(\mathrm{m})$ Auto Rmk
LAYER 1
504
13
13 Moderate
513
13.5
13.5 Good
Moderate
Good
1882

Ave.Vel Ave.Depth

$508.5 \quad 13.25$

$1861.5 \quad 0$

LAYER 3

REMARK:

Figure 6. First arrival times vs receiver offsets (Acquisition Point 3). 


\section{V L DATA PROCESSING}

Project Nam LVL STUDY Contractor:

Party/Proj M

Date Logger 6/15/2008

InstrU Type: McSEIS-160M

Processed ETAYO

Record No: 4

FIELD DATA

$\operatorname{Depth}(\mathrm{m})$ FB(mSec) FB_2(Reverse)

$\begin{array}{rrr}5 & 10 & 10 \\ 10 & 18.5 & 18 \\ 15 & 28.5 & 28.5 \\ 20 & 38 & 38 \\ 30 & 58.5 & 59 \\ 40 & 70 & 71 \\ 50 & 78 & 78.5 \\ 60 & 84 & 84 \\ 70 & 88 & 89 \\ 75 & 90 & 90 \\ 80 & 93 & 94 \\ 85 & 95 & 95\end{array}$

VELOCITY ANALYSIS

$\begin{array}{ll}\text { UPhole No: } & 4 \\ \text { Station No: } & 5613-2419 \\ \text { Easting: } & 493860.2 \\ \text { Northing: } & 135202.4 \\ \text { Elevation: } & 38.2 \\ \text { Drilled by: } & \\ \text { Datum(m): } & 0\end{array}$

$\begin{array}{ll}\text { Drilled Depth }(\mathrm{m}): & 1 \\ \text { Logged Depth }(\mathrm{m}): & 0.8 \\ \text { Shot Depth }(\mathrm{m}): & 0.8 \\ \text { Offset Dist }(\mathrm{m}): & 0 \\ \text { Source Type: } & \text { DYNAMITE } \\ \text { Delay TimeBreak: } & \\ \text { Static(millisecond): } & 40\end{array}$

Shot - Rec Offest(meters)
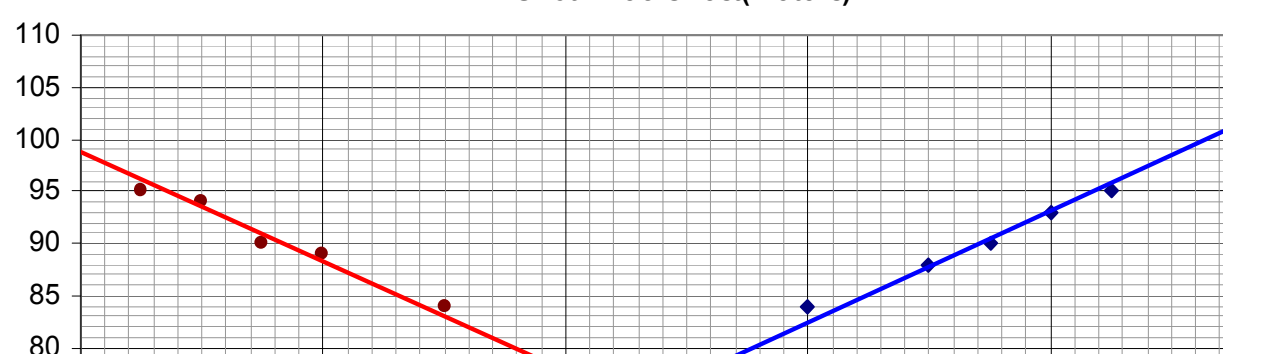

.
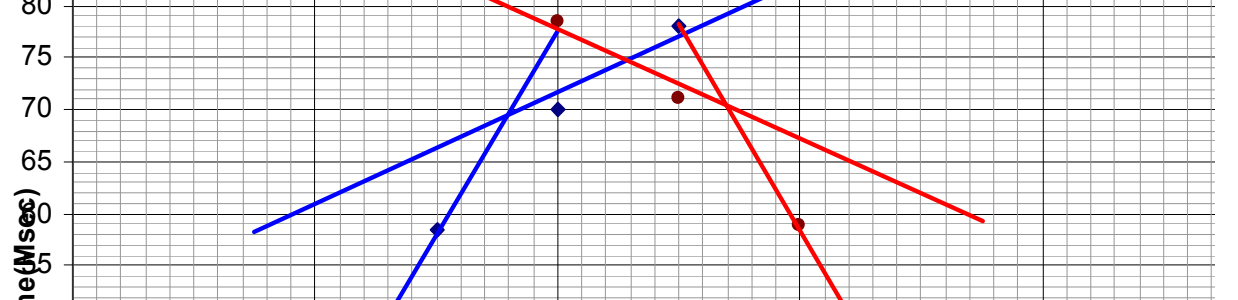

$\$ 0$

45

40

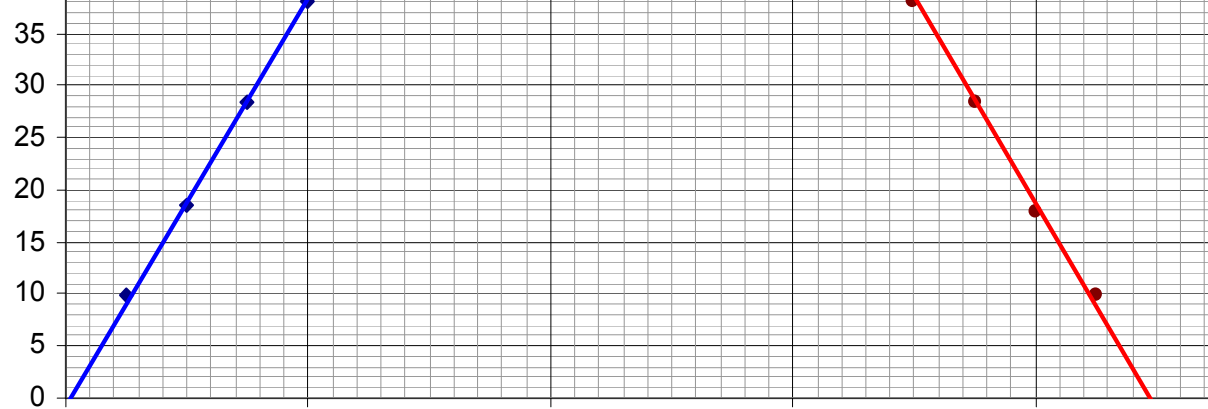

$\begin{array}{llll}0 & 20 & 40 & 60\end{array}$

$\operatorname{Vel}(\mathrm{m} / \mathrm{s})$ Thickness(Depth(m) Auto Rmk Vel(m/s) Thickness(Depth(m) Auto Rmk

\begin{tabular}{|c|c|c|c|c|c|c|c|c|c|c|}
\hline & $\operatorname{Vel}(\mathrm{m} / \mathrm{s})$ & Thickness( & Depth(m) & Auto Rmk & $\operatorname{Vel}(\mathrm{m} / \mathrm{s})$ & Thickness( & (Depth $(\mathrm{m})$ & Auto Rmk & Ave.Vel & Ave.Depth \\
\hline LAYER 1 & 511 & 13.4 & 13.4 & Good & 504 & 13.4 & 13.4 & Good & 507.5 & 13.4 \\
\hline LAYER 2 & 1839 & & & Weak & 1873 & & & Weak & 1856 & 0 \\
\hline LAYER 3 & & & & & & & & & 0 & 0 \\
\hline LAYER 4 & & & & & & & & & 0 & 0 \\
\hline
\end{tabular}

REMARK:

Figure 7. First arrival times vs receiver offsets (Acquisition Point 4). 


\section{V L DATA PROCESSING}

Project Nam LVL STUDY Contractor:

Party/Proj M

Date Logger 6/20/2008

InstrU Type: McSEIS-160M

Processed ETAYO

Record No: 5

FIELD DATA

$\operatorname{Depth}(\mathrm{m})$ FB(mSec) FB_2(Reverse)

$\begin{array}{rrr}5 & 9 & 9.5 \\ 10 & 19.5 & 20 \\ 15 & 26 & 26 \\ 20 & 39 & 39 \\ 30 & 57 & 57.5 \\ 40 & 68.5 & 69 \\ 50 & 74 & 75 \\ 60 & 79 & 80 \\ 70 & 84.5 & 84.5 \\ 75 & 88.5 & 88 \\ 80 & 90.5 & 90 \\ 85 & 93 & 94\end{array}$

VELOCITY ANALYSIS

$\begin{array}{ll}\text { UPhole No: } & 5 \\ \text { Station No: } & 5513-2259 \\ \text { Easting: } & 493359 \\ \text { Northing: } & 130202.3 \\ \text { Elevation: } & 35.3 \\ \text { Drilled by: } & \\ \text { Datum(m): } & 0\end{array}$

Drilled Depth(m):

Logged Depth(m): $\quad 0.8$

Shot Depth $(\mathrm{m}): \quad 0.8$

Offset Dist(m): $\quad 0$

Source Type: DYNAMITE

Delay TimeBreak:

Static(millisecond): $\quad 37$

\section{DISTANCE TIME GRAPH

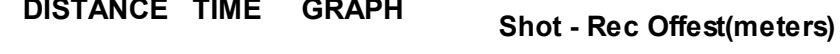

LAYER 1

LAYER 2

LAYER 3

LAYER 4

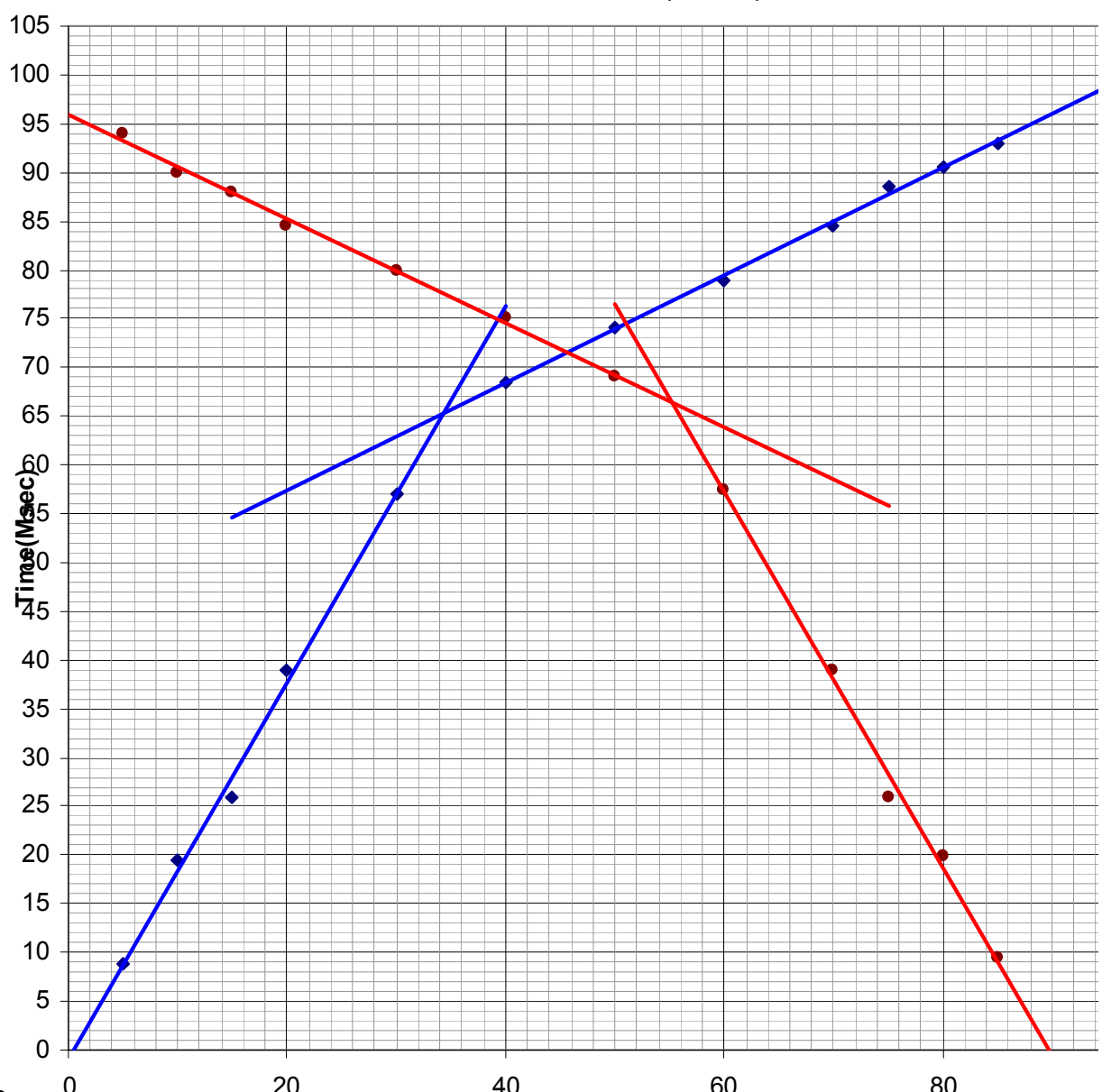

40

60

Ave.Vel Ave.Depth

$516.5 \quad 12.65$

$1834.5 \quad 0$

REMARK:

Figure 8. First arrival times vs receiver offsets (Acquisition Point 5). 


\section{V L DATA PROCESSING}

Project Nam LVL STUDY Contractor:

Party/Proj M

Date Logger 6/20/2008

InstrU Type: McSEIS-160M

Processed ETAYO

Record No: 6

FIELD DATA

$\begin{array}{ll}\text { UPhole No: } & 6 \\ \text { Station No: } & 5453-2259 \\ \text { Easting: } & 493359.5 \\ \text { Northing: } & 127202.1 \\ \text { Elevation: } & 32.2 \\ \text { Drilled by: } & \\ \text { Datum(m): } & 0\end{array}$

$\operatorname{Depth}(\mathrm{m})$ FB(mSec) FB_2(Reverse)

$\begin{array}{rrr}5 & 9 & 9 \\ 10 & 19 & 19 \\ 15 & 28 & 27.5 \\ 20 & 38 & 38.5 \\ 30 & 57.5 & 57.5 \\ 40 & 67 & 68.5 \\ 50 & 73.5 & 72 \\ 60 & 78.5 & 78 \\ 70 & 84.5 & 85 \\ 75 & 88 & 88 \\ 80 & 89 & 90 \\ 85 & 91.5 & 92\end{array}$

VELOCITY ANALYSIS

$\operatorname{Vel}(\mathrm{m} / \mathrm{s})$ Thickness(Depth(n

LAYER 1

LAYER 2

LAYER 3

LAYER 4
12.3

1812

\section{DISTANCE TIME}

$\begin{array}{ll}\text { Drilled Depth }(\mathrm{m}): & 1 \\ \text { Logged Depth }(\mathrm{m}): & 0.8 \\ \text { Shot Depth }(\mathrm{m}): & 0.8 \\ \text { Offset Dist }(\mathrm{m}): & 0 \\ \text { Source Type: } & \text { DYNAMITE } \\ \text { Delay TimeBreak: } & \\ \text { Static(millisecond): } & 35\end{array}$

APH

Shot - Rec Offest(meters)

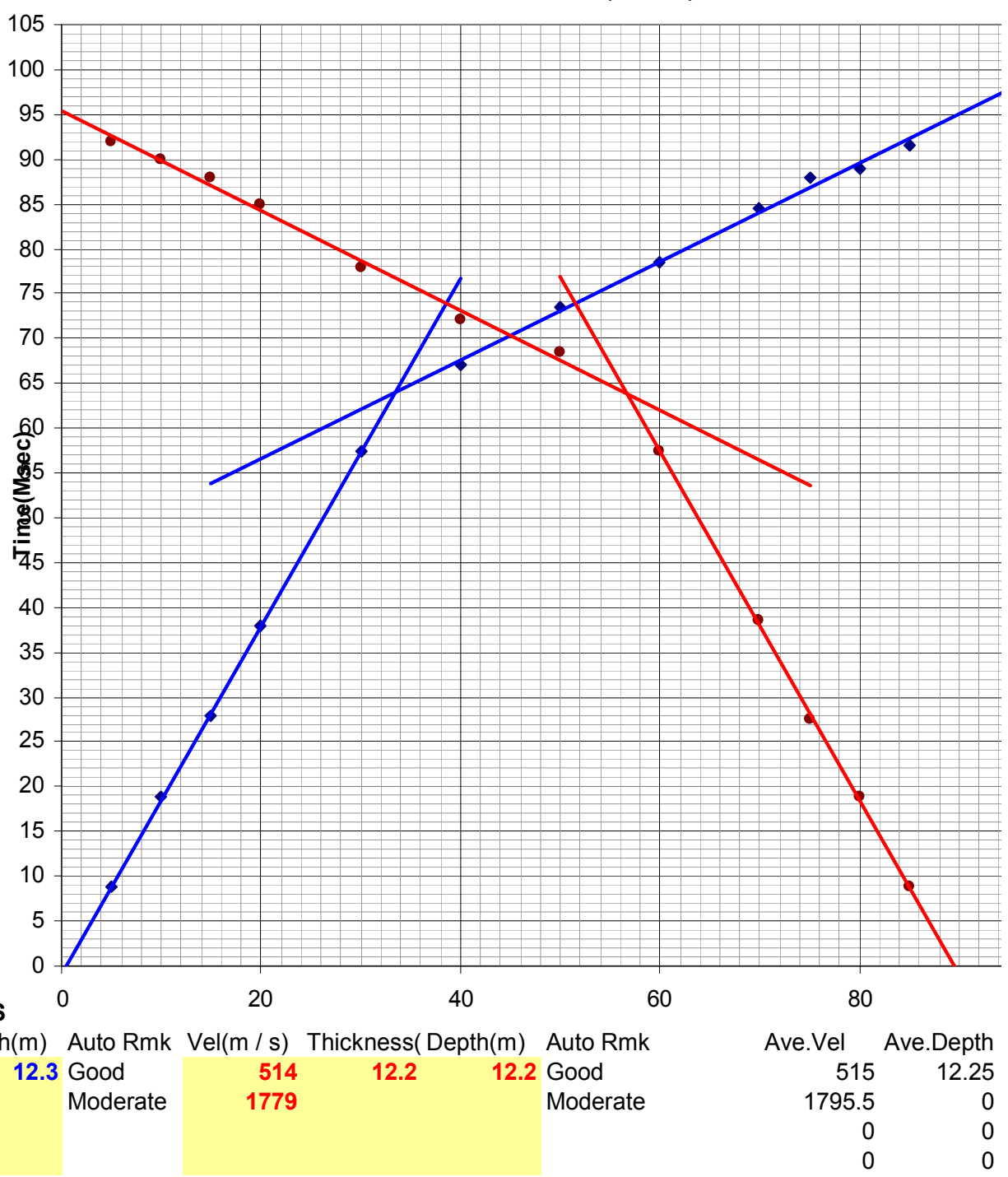

REMARK:

Figure 9. First arrival times vs receiver offsets (Acquisition Point 6). 


\section{V L DATA PROCESSING}

Project Nam LVL STUDY

Contractor:

Party/Proj M

Date Logger 6/23/2008

InstrU Type: McSEIS-160M

Processed ETAYO

Record No: 7

\section{FIELD DATA}

$\operatorname{Depth}(m) \quad F B(m S e c)$ FB_2(Reverse)

$\begin{array}{rrr}5 & 10 & 10 \\ 10 & 18 & 18 \\ 15 & 28 & 27.5 \\ 20 & 38 & 38 \\ 30 & 58 & 58 \\ 40 & 68 & 68.5 \\ 50 & 74 & 74.5 \\ 60 & 80 & 80 \\ 70 & 84 & 84 \\ 75 & 88 & 88 \\ 80 & 90.5 & 90 \\ 85 & 92.5 & 93\end{array}$

VELOCITY ANALYSIS

$\begin{array}{ll}\text { UPhole No: } & 7 \\ \text { Station No: } & 5453-2179 \\ \text { Easting: } & 497359.5 \\ \text { Northing: } & 127202.1 \\ \text { Elevation: } & 32.4 \\ \text { Drilled by: } & \\ \text { Datum(m): } & 0\end{array}$

Drilled Depth $(\mathrm{m})$ :

Logged Depth $(\mathrm{m}): \quad 0.8$

Shot Depth $(\mathrm{m})$ : $\quad 0.8$

Offset Dist(m): $\quad 0$

Source Type: DYNAMITE

Delay TimeBreak:

Static(millisecond): $\quad 35$

\section{DISTANCE TIME GRAPH \\ Shot - Rec Offest(meters)}

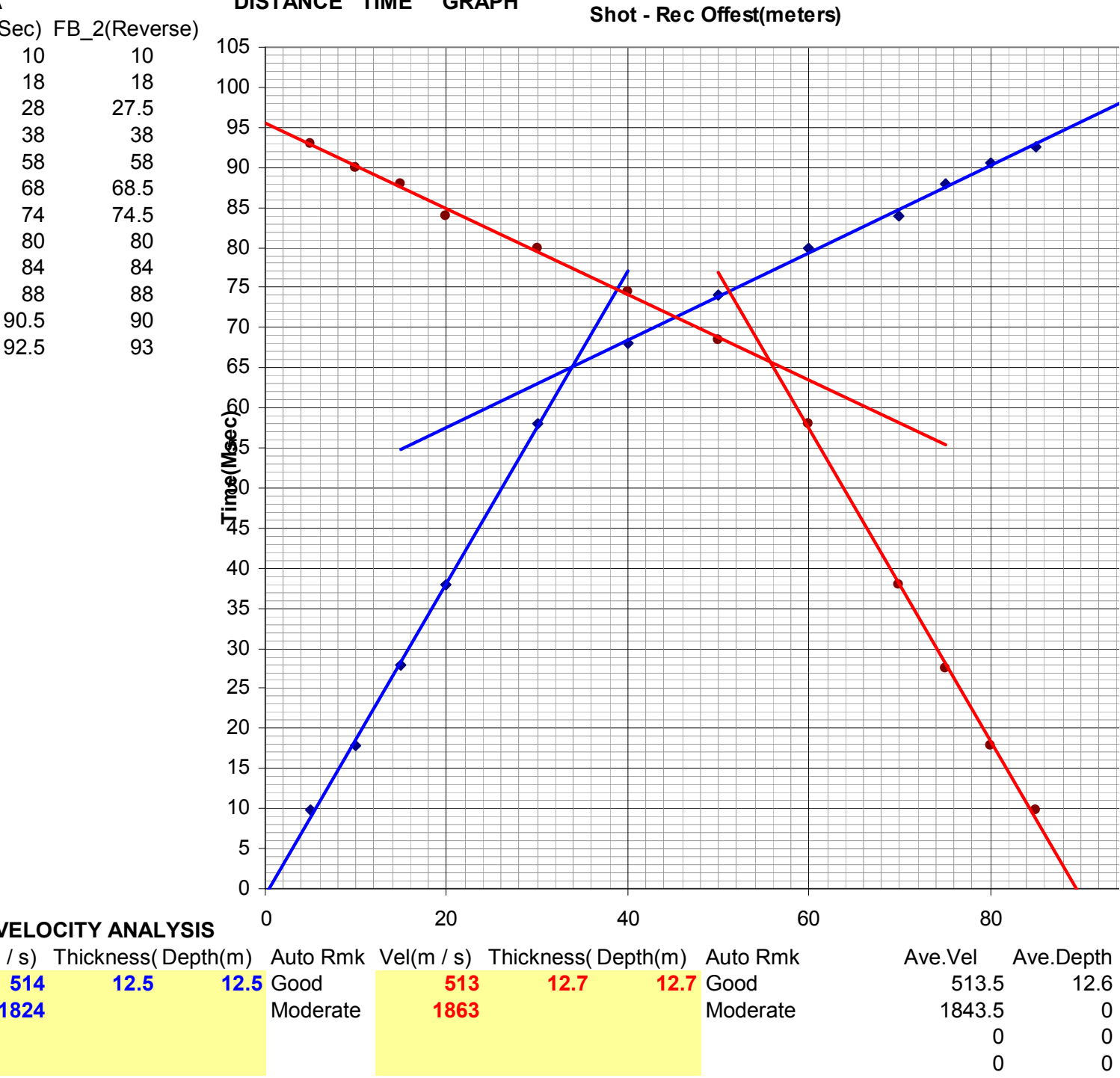

\section{LAYER 1}

LAYER 2

LAYER 3

LAYER 4

REMARK:
Figure 10. First arrival times vs receiver offsets (Acquisition Point 7) 


\section{V L DATA PROCESSING}

\begin{tabular}{|c|c|c|}
\hline \multirow{2}{*}{\multicolumn{3}{|c|}{ Project Nam LVL STUDY }} \\
\hline & & \\
\hline \multicolumn{3}{|l|}{ Party/Proj M } \\
\hline \multicolumn{3}{|c|}{ Date Logge، $6 / 23 / 2008$} \\
\hline \multicolumn{3}{|c|}{ InstrU Type: McSEIS-160M } \\
\hline \multicolumn{3}{|c|}{ Processed ETAYO } \\
\hline \multicolumn{3}{|c|}{ Record No: 8} \\
\hline \multicolumn{3}{|c|}{ FIELD DATA } \\
\hline $\operatorname{Depth}(\mathrm{m})$ & $\mathrm{FB}(\mathrm{mSec})$ & FB_2(Reve \\
\hline 5 & 9.5 & 9 \\
\hline 10 & 18.5 & 19 \\
\hline 15 & 27 & 27.5 \\
\hline 20 & 37 & 37.5 \\
\hline 30 & 56.5 & 57 \\
\hline 40 & 69 & 69.5 \\
\hline 50 & 75 & 75 \\
\hline 60 & 80 & 78.5 \\
\hline 70 & 84 & 85 \\
\hline 75 & 88.5 & 88 \\
\hline 80 & 91.5 & 90 \\
\hline 85 & 94 & 93.5 \\
\hline
\end{tabular}

$\begin{array}{ll}\text { UPhole No: } & 8 \\ \text { Station No: } & 5533-2179 \\ \text { Easting: } & 497359.5 \\ \text { Northing: } & 130702.3 \\ \text { Elevation: } & 35.1 \\ \text { Drilled by: } & \\ \text { Datum(m): } & 0\end{array}$

$\begin{array}{ll}\text { Drilled Depth }(m): & 1 \\ \text { Logged Depth }(\mathrm{m}): & 0.8 \\ \text { Shot Depth }(\mathrm{m}): & 0.8 \\ \text { Offset Dist }(\mathrm{m}): & 0 \\ \text { Source Type: } & \text { DYNAMITE } \\ \text { Delay TimeBreak: } & \\ \text { Static(millisecond): } & 37\end{array}$

GRAPH

Shot - Rec Offest(meters)

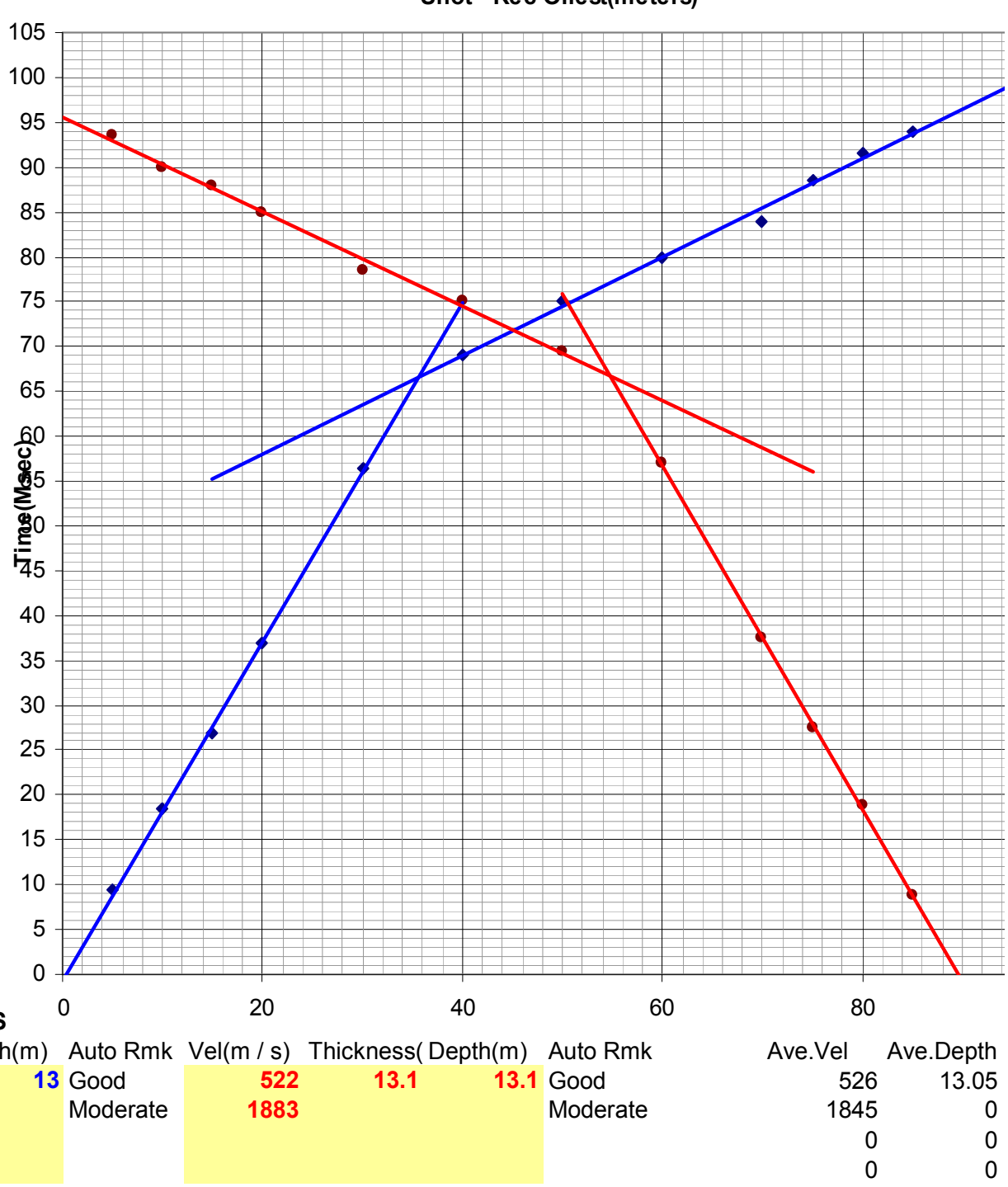

REMARK:

Figure 11. First arrival times vs receiver offsets (Acquisition Point 8). 


\section{V L DATA PROCESSING}

Project Nam LVL STUDY

Contractor:

Party/Proj M

Date Logger 6/23/2008

InstrU Type: McSEIS-160M

Processed ETAYO

Record No: 9

\section{FIELD DATA}

epth $(m) \quad F B(m S e$

$\begin{array}{rrr}5 & 8 & 8.5 \\ 10 & 19 & 18.5 \\ 15 & 27 & 27 \\ 20 & 36.5 & 37 \\ 30 & 54 & 55 \\ 40 & 68 & 68.5 \\ 50 & 75 & 75 \\ 60 & 80 & 80 \\ 70 & 85 & 85 \\ 75 & 88.5 & 88 \\ 80 & 91 & 91 \\ 85 & 93 & 92.5\end{array}$

VELOCITY ANALYSIS

$\begin{array}{ll}\text { UPhole No: } & 9 \\ \text { Station No: } & 5613-2179 \\ \text { Easting: } & 497860.2 \\ \text { Northing: } & 135202.4 \\ \text { Elevation: } & 38.6 \\ \text { Drilled by: } & \\ \text { Datum(m): } & 0\end{array}$

Drilled Depth $(\mathrm{m})$ : $\quad 1$

Logged Depth $(\mathrm{m}): \quad 0.8$

Shot Depth $(\mathrm{m})$ : $\quad 0.8$

Offset Dist(m): $\quad 0$

Source Type: DYNAMITE

Delay TimeBreak:

Static(millisecond): $\quad 38$

\section{DISTANCE TIME GRAPH \\ Shot - Rec Offest(meters)}

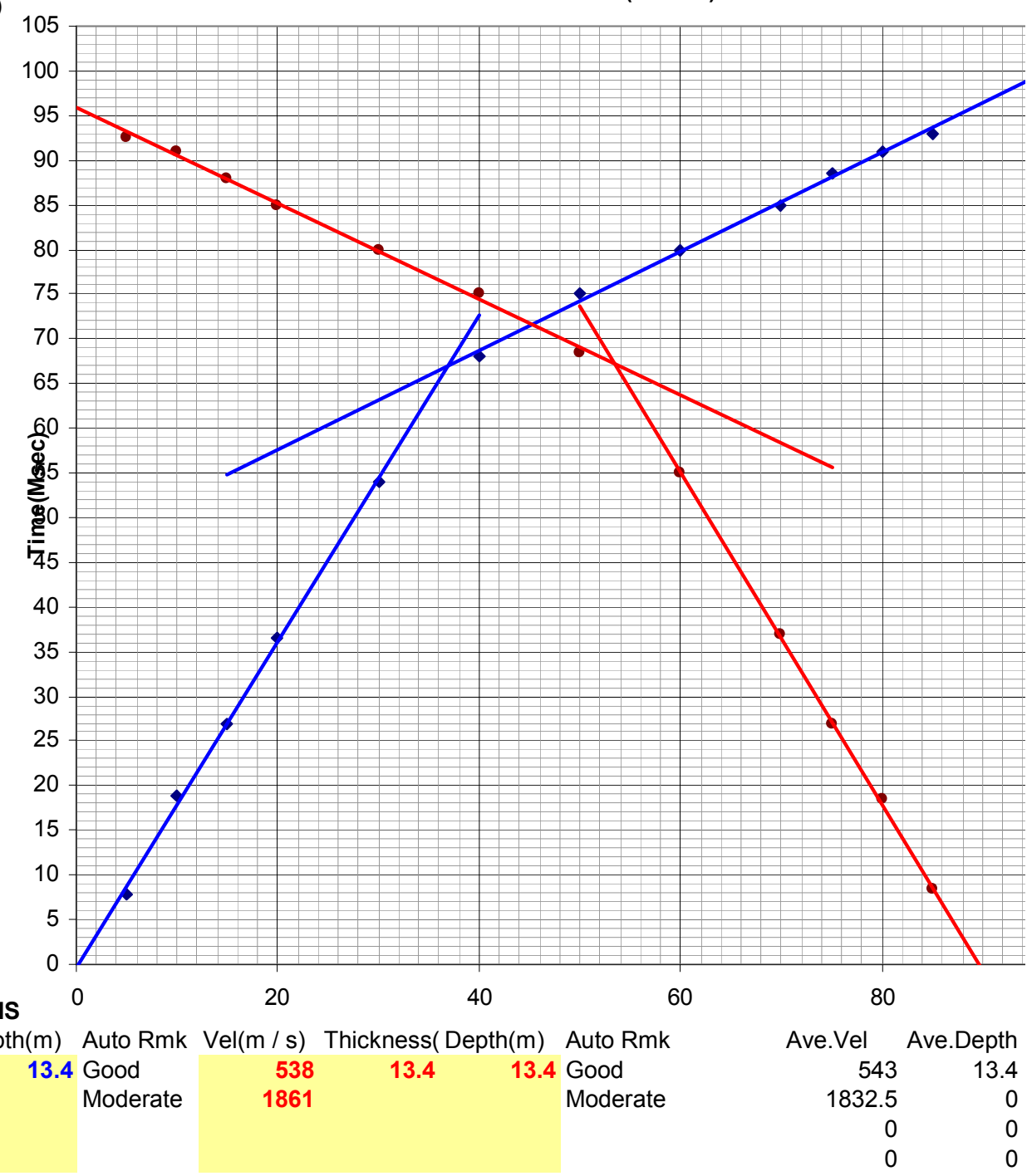

REMARK:

Figure 12. First arrival times vs receiver offsets (Acquisition Point 9). 


\section{V L DATA PROCESSING}

\begin{tabular}{|c|c|c|}
\hline \multirow{2}{*}{\multicolumn{3}{|c|}{ Project Nam LVL STUDY }} \\
\hline & & \\
\hline \multicolumn{3}{|l|}{ Contractor: } \\
\hline \multicolumn{3}{|l|}{ Party/Proj M } \\
\hline \multicolumn{3}{|c|}{ Date Logge، $6 / 27 / 2008$} \\
\hline \multicolumn{3}{|c|}{ InstrU Type: McSEIS-160M } \\
\hline \multicolumn{3}{|c|}{ Processed ETAYO } \\
\hline \multicolumn{3}{|c|}{ Record No: 10} \\
\hline \multicolumn{3}{|c|}{ FIELD DATA } \\
\hline Depth(m) & $\mathrm{FB}(\mathrm{mSec})$ & FB_2(Re \\
\hline 5 & 8 & 8 \\
\hline 10 & 19 & 19 \\
\hline 15 & 26.5 & 27 \\
\hline 20 & 36 & 37 \\
\hline 30 & 53.5 & 54 \\
\hline 40 & 68 & 68.5 \\
\hline 50 & 74 & 74 \\
\hline 60 & 79.5 & 80 \\
\hline 70 & 84 & 84 \\
\hline 75 & 87 & 88 \\
\hline 80 & 90 & 90 \\
\hline 85 & 92 & 92.5 \\
\hline
\end{tabular}

\begin{tabular}{llll} 
UPhole No: 10 & Drilled Depth $(\mathrm{m}):$ & 1 \\
Station No: & $\mathbf{5} 613-2099$ & Logged Depth $(\mathrm{m}):$ & 0.8 \\
Easting: & 501860.2 & Shot Depth $(\mathrm{m}):$ & 0.8 \\
Northing: & 135202.4 & Offset Dist $(\mathrm{m}):$ & 0 \\
Elevation: & 38.8 & Source Type: & DYNAMITE \\
Drilled by: & Delay TimeBreak: & \\
Datum(m): & 0 & Static(millisecond): & 38 \\
\multicolumn{1}{c}{ DISTANCE TIME } & GRAPH
\end{tabular}

\section{Shot-Rec Offest(meters)}

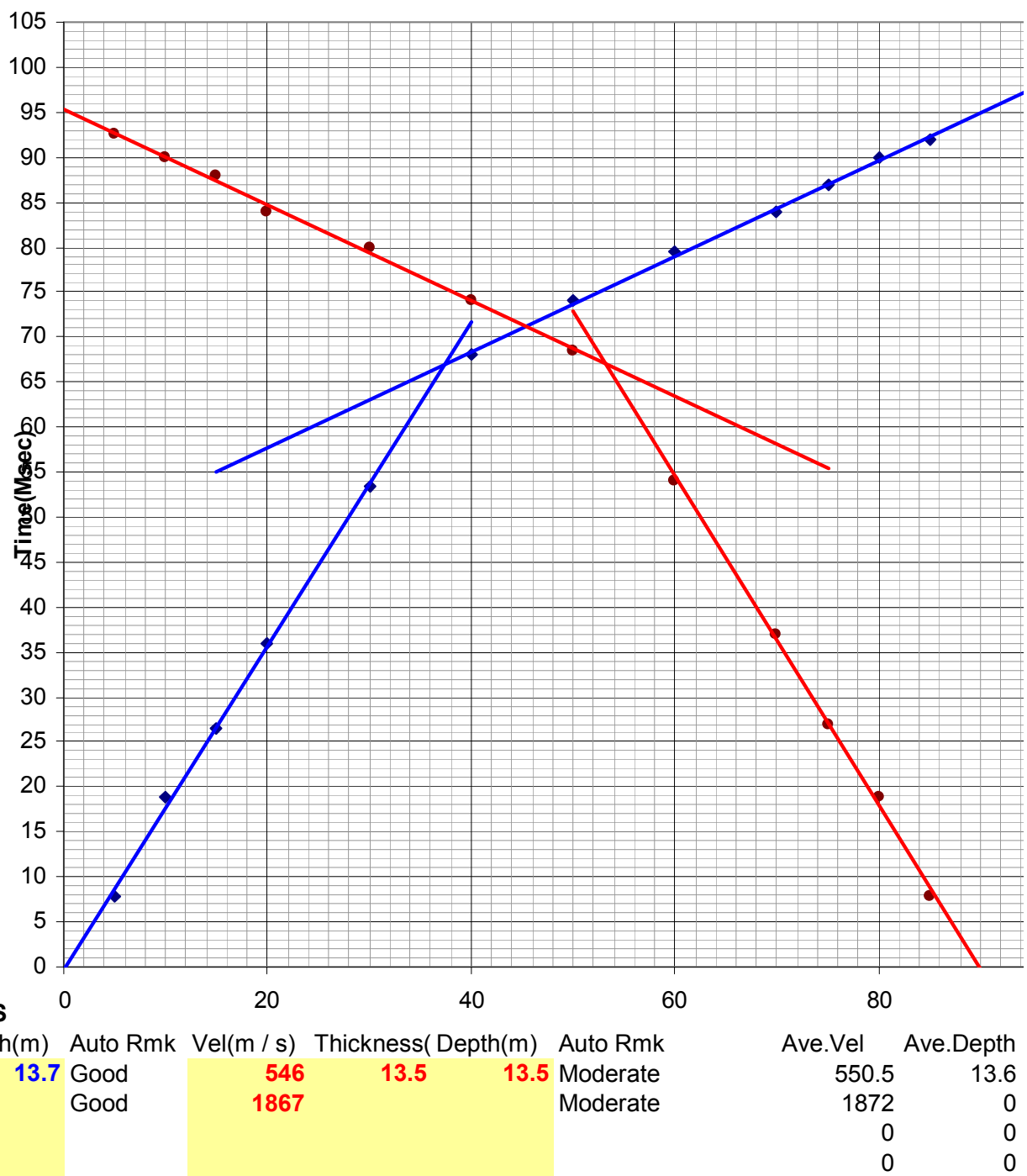

REMARK:

Figure 13. First arrival times vs receiver offsets (Acquisition Point 10). 


\section{V L DATA PROCESSING}

Project Nam LVL STUDY Contractor:

Party/Proj M

Date Logger 6/27/2008

InstrU Type: McSEIS-160M

Processed ETAYO

Record No: 11

FIELD DATA

$\operatorname{Depth}(\mathrm{m})$ FB(mSec) FB_2(Reverse)

$\begin{array}{rrr}5 & 9.5 & 10 \\ 10 & 19 & 19 \\ 15 & 28 & 27.5 \\ 20 & 37 & 37 \\ 30 & 55.5 & 56 \\ 40 & 68 & 68 \\ 50 & 74.5 & 75 \\ 60 & 79 & 78.5 \\ 70 & 84 & 84 \\ 75 & 87 & 87 \\ 80 & 90 & 90 \\ 85 & 93 & 93\end{array}$

VELOCITY ANALYSIS

$\begin{array}{ll}\text { UPhole No: } & 11 \\ \text { Station No: } & 5533-2099 \\ \text { Easting: } & 501359 \\ \text { Northing: } & 130702.4 \\ \text { Elevation: } & 35.3 \\ \text { Drilled by: } & \\ \text { Datum(m): } & 0\end{array}$

Drilled Depth $(m)$ :

Logged Depth $(m)$ :

Shot Depth $(\mathrm{m})$ :

Offset Dist(m):

Source Type:

Delay TimeBreak:

Static(millisecond)

DISTANCE TIME GRAPH

Shot - Rec Offest(meters)

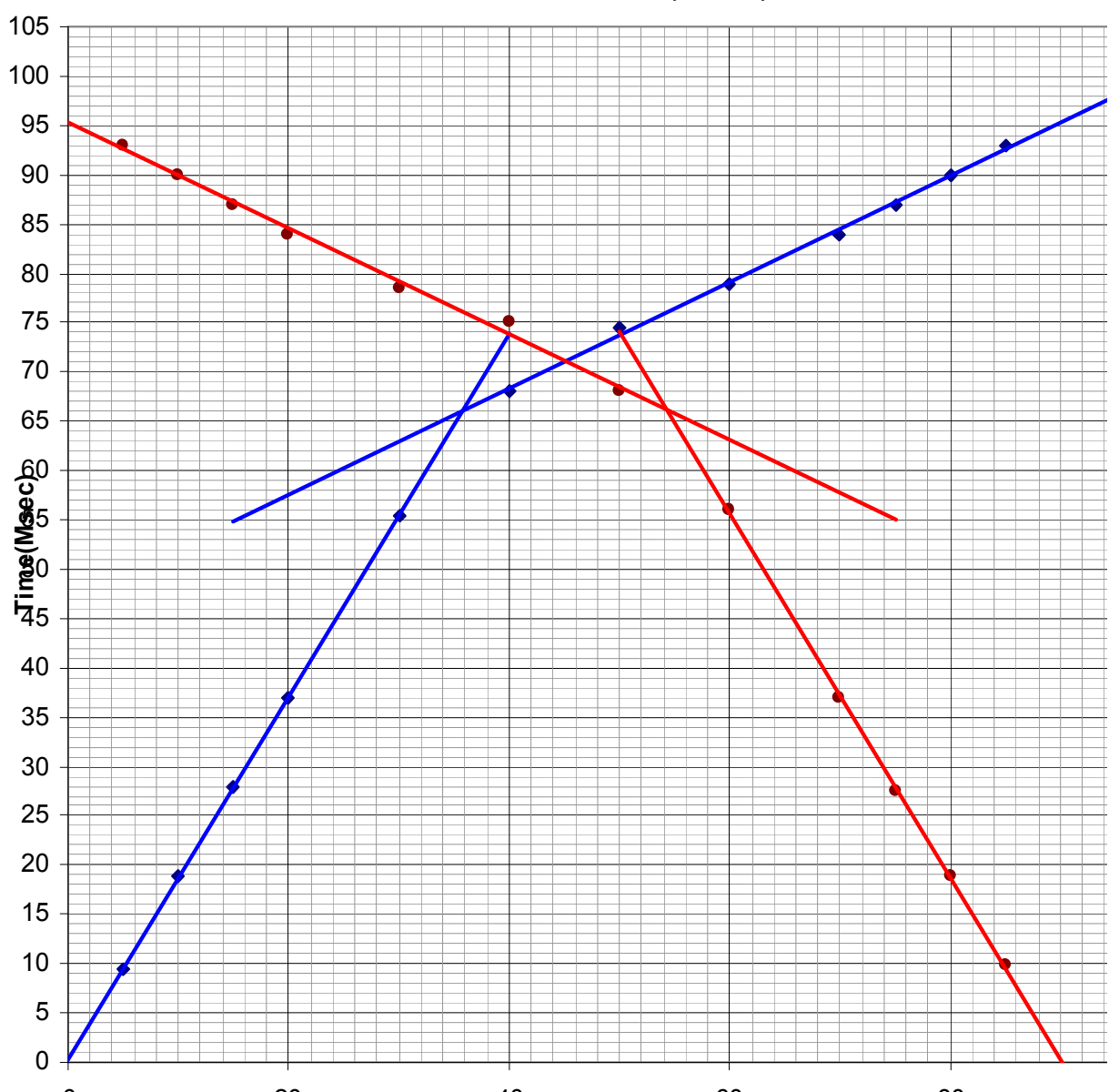

0

20

40

60

80

$\operatorname{Vel}(\mathrm{m} / \mathrm{s})$ Thickness(Depth $(\mathrm{m})$ Auto Rmk Vel(m/s) Thickness(Depth $(\mathrm{m})$ Auto Rmk

LAYER 1

LAYER 2 544

13.3

13.3 Good

542

13.3

13.3 Good

Moderate

Ave.Vel Ave.Depth

1845

Moderate

1850

LAYER 4

REMARK:

Figure 14. First arrival times vs receiver offsets (Acquisition Point 11). 


\section{V L DATA PROCESSING}

\begin{tabular}{|c|c|c|}
\hline Project Nam & LVL STUDY & \\
\hline Contractor: & & \\
\hline Party/Proj M & & \\
\hline Date Logger & $6 / 27 / 2008$ & \\
\hline InstrU Type: & McSEIS-160I & \\
\hline Processed E & TAYO & \\
\hline Record No: & & \\
\hline FIELD & DATA & \\
\hline Depth(m) & $\mathrm{FB}(\mathrm{mSec})$ & (R) \\
\hline 5 & 10 & 10 \\
\hline 10 & 18 & 18 \\
\hline 15 & 27 & 27.5 \\
\hline 20 & 36 & 37 \\
\hline 30 & 56 & 56.5 \\
\hline 40 & 67 & 67 \\
\hline 50 & 74.5 & 75 \\
\hline 60 & 79 & 78.5 \\
\hline 70 & 84 & 85 \\
\hline 75 & 87 & 87.5 \\
\hline 80 & 90 & 89.5 \\
\hline 85 & 92 & 91.5 \\
\hline
\end{tabular}

$\begin{array}{ll}\text { UPhole No: } & 12 \\ \text { Station No: } & 5453-2099 \\ \text { Easting: } & 501359 \\ \text { Northing: } & 127202.1 \\ \text { Elevation: } & 32.5 \\ \text { Drilled by: } & \\ \text { Datum(m): } & 0\end{array}$

DISTANCE TIME

$\begin{array}{ll}\text { Drilled Depth }(m): & 1 \\ \text { Logged Depth }(m): & 0.8 \\ \text { Shot Depth }(m): & 0.8 \\ \text { Offset Dist }(m): & 0 \\ \text { Source Type: } & \text { DYNAMITE } \\ \text { Delay TimeBreak: } & \\ \text { Static(millisecond): } & 35\end{array}$

Shot - Rec Offest(meters)
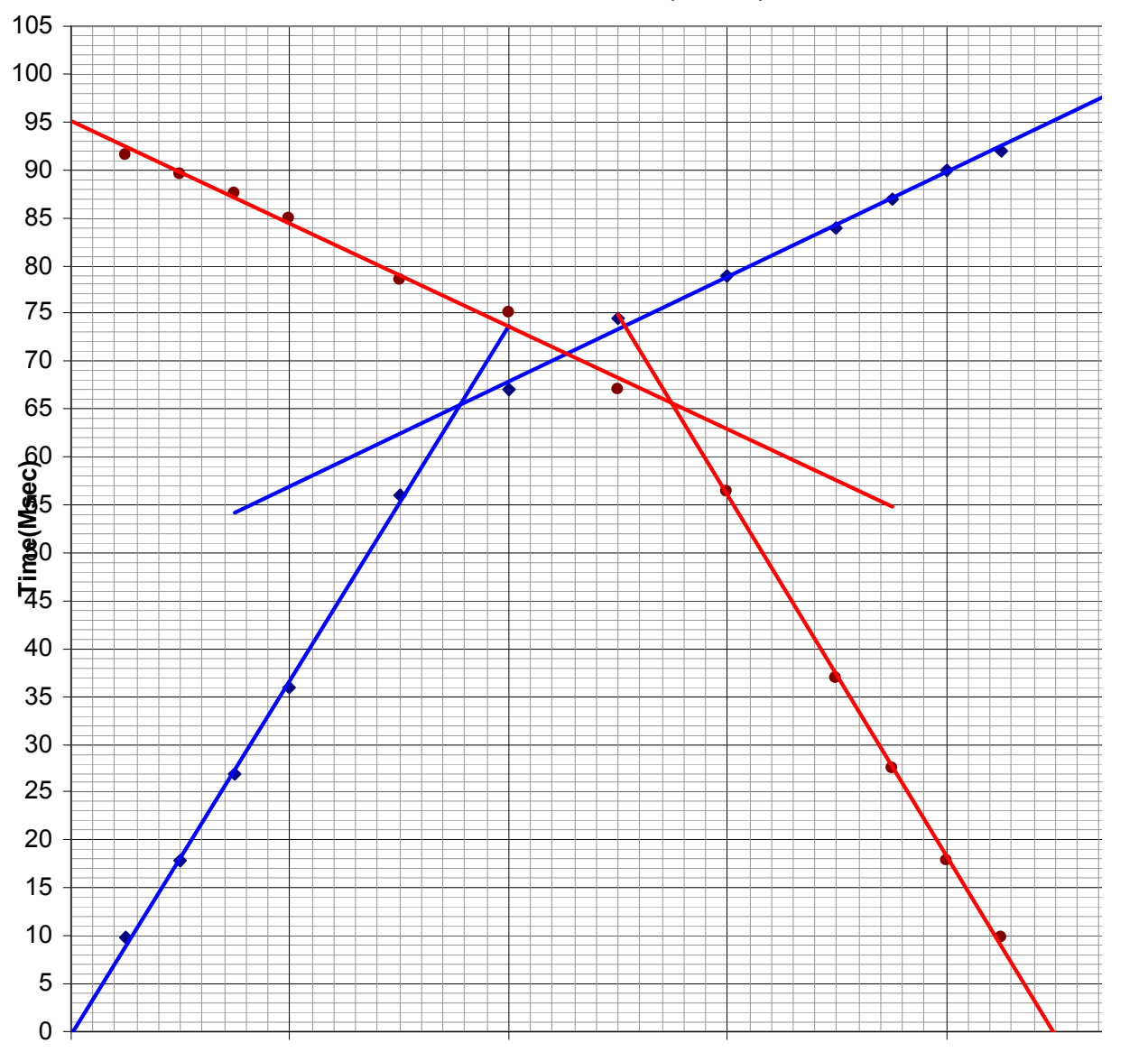

VELOCITY ANALYSIS

0

20

40

60

80

$\operatorname{Vel}(\mathrm{m} / \mathrm{s})$ Thickness(Depth $(\mathrm{m})$ Auto Rmk Vel(m/s) Thickness(Depth $(\mathrm{m})$ Auto Rmk

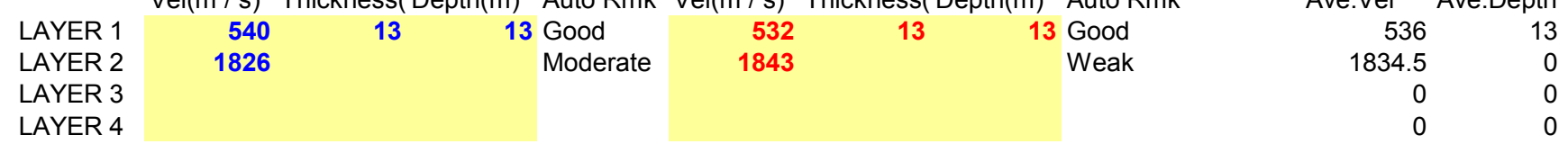

REMARK:

Figure 15. First arrival times vs receiver offsets (Acquisition Point 12).

\section{Conclusion}

The near surface investigation of the physical properties of the unconsolidated and consolidated layers has been carried out at Omerelu in Rivers State of Nigeria. Omerelu lies between latitude $05^{\circ} 08^{\prime} \mathrm{N}$ and $05^{\circ} 13^{\prime} \mathrm{N}$ and longitude $06^{\circ}$ $51^{\prime} \mathrm{E}$ and $06^{\circ} 58^{\prime} \mathrm{E}$. Refraction method was used to acquire the data. This involved identifying acquisition points and preparing the points for deployment of field equipment which included 12-geophone receiver array and OYO McSeis $160 \mathrm{M}$ recording instrument with capability to initiate the source and record signals from the subsurface transmitted through receivers.

In order to achieve the main of this study, the data were processed using Upsphere computer software which was written based on intercept time method. The slopes of the graphs gave velocity results and thickness of the unconsolidated layer was calculated. The depth of 
unconsolidated in the study area varied between 12 and 13.7 $\mathrm{m}$. The depth obtained indicates that in order to improve the signal to noise ratio, source depth should be placed below the unconsolidated layers. The velocities of the unconsolidated and the consolidated layers varied between $500 \mathrm{~m} / \mathrm{s}-550$ $\mathrm{m} / \mathrm{s}$ and $1790 \mathrm{~m} / \mathrm{s}-1875 \mathrm{~m} / \mathrm{s}$ respectively help to remove near surface effect. The results were applied to carry out static correction on reflection data and this produced alignment of the early arrivals.

This study also provides a baseline for single deep hole operations in the area.

\section{References}

[1] Ajani, O. O, Fajemiroye, J. A and Odumosu O. A., 2013. Study of near surface layers of Omerelu area using low velocity layer (LVL) method. International Journal of Developmental Sciences IJDS. 2 (1), 131-139.

[2] Asseez, L. O., 1976. Review of the stratigraphy, sedimentation and structure of the Niger Delta. Kogbe C. A. Rock review (Nig,) Ltd, Pub. 311-324.

[3] Chaubey, A. K., 2000. Seismic Reflection and Refraction Methods. Cambridge University Press, England: 214-221.

[4] Dobrin, M. B. 1985. Introduction to geophysical prospecting. McGraw-Hill Book Co, Inc., New York:100 - 110, 148-151, 222-226.

[5] Edge, A G, and Laby., T H., 1931. The principles and practice of geophysical exploration: Cambridge University Press, London, 339-340.

[6] Enikanselu, P. A., 2008. "Geophysical Seismic Refraction and Uphole Survey Analysis of Weathered Layer Characteristics in the "Mono" Field, North Western Niger Delta" in Proceedings of National Workshop on Geophysical Seismic Analysis, Delta State, Nigeria, pp. 1-7.

[7] Espey, H. R., 1981. Seismic field techniques. Geotran Inc, Los Angeles: VI 24-27.
[8] Galitzin. mines. edu., 2002. Exploration Geophysics: Refraction Seismic Notes. 2002: 1-55.

[9] Hawkins, L. V., 1961. The Reciprocal method of routine shallow seismic refraction investigations: Geophysics, 26, 806-819.

[10] Jones, I. F., 2013. Tutorial: Seismic response to strong vertical velocity change, first break, 31(6), 79-90.

[11] Krawczyk, C. M., Polon, U., and Beilecke, T., 2013. Shear wave reflection seismics as a valuable tool for near - surface urban applications. The Leading Edge, 32, 256-263.

[12] Lankston, R. W., 1990. High-resolution refraction seismic data acquisition and interpretation, in Ward, S. H., editor, Geotechnical and Environmental Geophysics, Volume 1: Review and Tutorial: Society of Exploration Geophysicists: 344-390.

[13] Lowrie W,. 2007. Fundamentals of Geophysics, Cambridge University Press, England: 83 - 98, 145-147.

[14] Nettleton, L. L., 1940. Geophysical prospecting for oil: McGraw-Hill Book Co., New York: 444.

[15] Okwueze E., 1996. Shell Intensive Training Programme (Geophysics: Seismic methods lectures): 24-46.

[16] Palmer, D., 1980. The generalized reciprocal method seismic refraction interpretation. Soc of Explo. Geophys.

[17] Uko, E. T., Emudlanughe, J. E and Eze, C. L., 2016. Comparison of the characteristics of Low Velocity Layer (LVL) in the Mangrove swamp and in upper flood plain Environment in the Niger Delta using Seismic refraction method. Journal of Geology and Geophysics 5: 248. 1-8.

[18] Telford, W. M., L. P. Geldart, and R E Sheriff., 1990. Applied Geophysics, 2nd ed., Cambridge University Press.

[19] Weber, K. J., 1971. Sedimentological aspects of oil fields in the Niger Delta 50: 559-576.

[20] Wojciech Czuba (2017). 3-D Seismic tomographic modeling of the crustal structure of Northwestern Svalbard based on deep seismic sounding. Geophys J Int 208(1): 508-520. 